\title{
Comparison of Ocean Dynamics with a Regional Circulation Model and Improved Altimetry in the North-Western Mediterranean
}

\author{
Jérôme Bouffard ${ }^{1, *}$, Stefano Vignudelli ${ }^{2}$, Marine Herrmann ${ }^{3}$, Florent Lyard ${ }^{1}$, Patrick Marsaleix ${ }^{3}$, \\ Yves Ménard ${ }^{4}$, and Paolo Cipollini ${ }^{5}$ \\ ${ }^{1}$ Laboratory of Spatial, Geophysical and Oceanographic Studies (LEGOS), Toulouse, France \\ ${ }^{2}$ National Research Council (CNR), Biofisica Institute, Pisa, Italia \\ ${ }^{3}$ Laboratory of Aerology (LA), 31400 Toulouse, France \\ ${ }^{4}$ French Space Agency (CNES), 31400 Toulouse, France \\ ${ }^{5}$ National Oceanography Centre of Southampton (NOCS), Southampton, UK
}

Received 15 November 2006, accepted 8 June 2007

\begin{abstract}
The spatial and temporal resolution of satellite altimetry is usually sufficient for monitoring the changes of sea surface topography in the open ocean. However, coastal ocean dynamics are much more complex, being characterized by smaller spatial and temporal scales of variability. The quality and availability of satellite-derived products along the coasts have to be improved, with a strategy optimized for coastal targets. Therefore a coastal multi-satellite altimetry dataset (TOPEX/Poseidon, Jason-1; Envisat; GFO) at a $10-20 \mathrm{~Hz}$ sampling rate has been derived from routine geophysical data products using a new processing software dedicated to coastal zone applications. Improved along-track sea level variations with fine space scales are available in the North-western Mediterranean Sea from 2001 to 2003, and are compared with high-resolution numerical model elevations from the eddy-resolving model SYMPHONIE. This preparatory work emphasizes the potential of improved multi-satellite altimetry for validating coastal hydro-dynamical models and could contribute in the future to a better tuning of the boundary conditions of the simulations.
\end{abstract}

Key words: Coastal altimetry, Boussinesq model, Mediterranean Sea, Coastal modelling

Citation: Bouffard, J., S. Vignudelli, M. Herrmann, F. Lyard, P. Marsaleix, Y. Ménard, and P. Cipollini, 2008: Comparison of ocean dynamics with a regional circulation model and improved altimetry in the North-western Mediterranean. Terr. Atmos. Ocean. Sci., 19, 117-133, doi: 10.3319/TAO.2008.19.1$2.117(S A)$

\section{INTRODUCTION}

The coastal ocean, by virtue of its location, is of crucial societal importance. Despite its relatively small surface in comparison to the entire ocean, it contributes to approximately $43 \%$ of the estimated total value of ecosystem services (Costanza et al. 1997). A quantitative understanding of the physical processes that impact on the coastal region dynamics is necessary to determine how changes in land use, climate, and sea level will affect coastal systems. Therefore, there is a need for development of adequate and integrated management strategies for the coastal environment.

Satellite altimeters provide repetitive views of phenomena and properties unachievable by other means, and

\footnotetext{
* Corresponding author

E-mail:bouffard@notos.cst.cnes.fr
}

although current missions are not well suited to cover the broad range of space and time scales associated with coastal applications, their use seems promising to provide useful and consistent regional datasets for managing impacts in the coastal zone.

However, the information from satellite altimeters is restricted to either the surface layer of the ocean (currents) or to some water-column integrated quantities such as sea level variability. It is important, therefore, to assimilate these datasets as a part of a comprehensive monitoring system, which includes modelling, and to link with systematic measurements of the ocean interior.

In this framework, the main purpose of the present study is to assess the ability of an improved coastal altimetry dataset to validate a Boussinesq oceanic circulation model. 
Firstly, we will present the study area and its main dynamical features. Secondly, we will focus on the model characteristics, on the strategy of building an improved coastal altimetric dataset, including its validation and the procedure to make Boussinesq model sea level variations as homogeneous as possible with altimetric sea level anomalies. Finally we will show some qualitative and quantitative results concerning the spatial and temporal agreement between the model and the altimeter-derived sea level variations.

This preparatory work emphasizes the potential of an improved multi-satellite altimetry dataset for validating coastal hydro-dynamical models. It also constitutes a first step in order to assimilate improved coastal altimetric data in such models in order to better resolve small dynamical processes at the interface of the open ocean and the coastal zone.

\section{STUDY AREA}

The study area is the North-western Mediterranean Sea (Fig. 1). The major dynamical feature of the North-western Mediterranean Sea is the Liguro-Provencal-Catalan current (hereafter the LPC, see Fig. 1). This cyclonic coastal current originates in the Gulf of Genoa from the merging of the Eastern and Western Corsica current (see Fig. 1). Its transport is equivalent to the transport of Atlantic water entering the Gibraltar Strait as shown by earlier studies (Lacombe and Tchernia 1972; Béthoux 1980), which is about $1.5 \mathrm{~Sv}$. Wind driven and local climate changes have a strong impact on the LPC (Estournel et al. 2003). This density current is strongly marked by seasonal variability (Gostan 1967).

From June to December, geostrophic component velocity indicates a large and shallow current. At the surface it is about 40 to $50 \mathrm{~km}$ wide with a velocity of $50 \mathrm{~cm} \mathrm{~s}^{-1}$. The current is reduced at deeper levels being only $10 \mathrm{~km}$ wide at $100-200 \mathrm{~m}$ depth, with a mean velocity of about $10 \mathrm{~cm} \mathrm{~s}^{-1}$. In winter, from January to mid-March, the LPC is deeper, narrower (20 - $30 \mathrm{~km}$ wide) and closer to the coast, and the geostrophic velocities increase. At 250 - $500 \mathrm{~m}$ depth and $10 \mathrm{~km}$ from the coastline, they are about $10 \mathrm{~cm} \mathrm{~s}^{-1}$ (Millot 1991). In spring, the LPC widens and slows down. The winter flow is unstable and generates meanders until Marseilles (Conan and Millot 1995). These meanders have spatial scales of variability of only $10-20 \mathrm{~km}$ and are separated by a few tens to one hundred kilometres. They can evolve into eddies.

It should be noted that in the coastal area of the Ligurian Sea (10 km off the coast), the mean current is not very strong but is characterized by significant mesoscale variability. This is one of the reasons why the prediction of the oceanic circulation in this zone is difficult (Alberola et al. 1995; Sammari et al. 1995). In the Catalan Sea, the LPC accelerates along the continental slope of the Balearic Islands. Its seasonal variability is comparable to that observed in the Ligurian Sea with a maximum activity during winter and a minimum at the end of the summer (Font et al. 1995).

Observing and predicting such complex dynamics is still a challenging issue given the wide range of interacting spatial and temporal scales of variability. Several efforts have been made to improve the knowledge of the ocean dynamics in the North-western Mediterranean by combining modelling and observations (e.g., Ahumada and Cruzado 2006; Jordi et al. 2006; Taillandier et al. 2006).

Our contribution is to introduce improved altimetric data, adapted for the coastal zone, in order to validate the eddy-resolving Boussinesq model which simulates the small-scale coastal dynamics. It should be noted that the validation results presented here, between a new coastal altimetry dataset and the regional circulation model, represent an important step forward the future assimilation of coastal altimetry in Boussinesq regional models.

\section{DATA AND METHODS}

\subsection{SYMPHONIE: A Boussinesq Model Implemented in the North-Western Mediterranean Sea}

The model used has been implemented in a regional configuration in the framework of the Mediterranean Ocean Forecasting System toward Environmental Prediction project (hereafter MFSTEP, details given in the acknowledgment section). The 3-D primitive equation coastal ocean model SYMPHONIE is described in detail in Estournel et al. (1997) and Marsaleix et al. (2006). It has recently been used to study the circulation in the Gulf of Lions (Estournel et al. 2003; Petrenko et al. 2005; Gatti et al. 2006), the circulation in the Bay of Fos (Ulses et al. 2005) and the Bay of

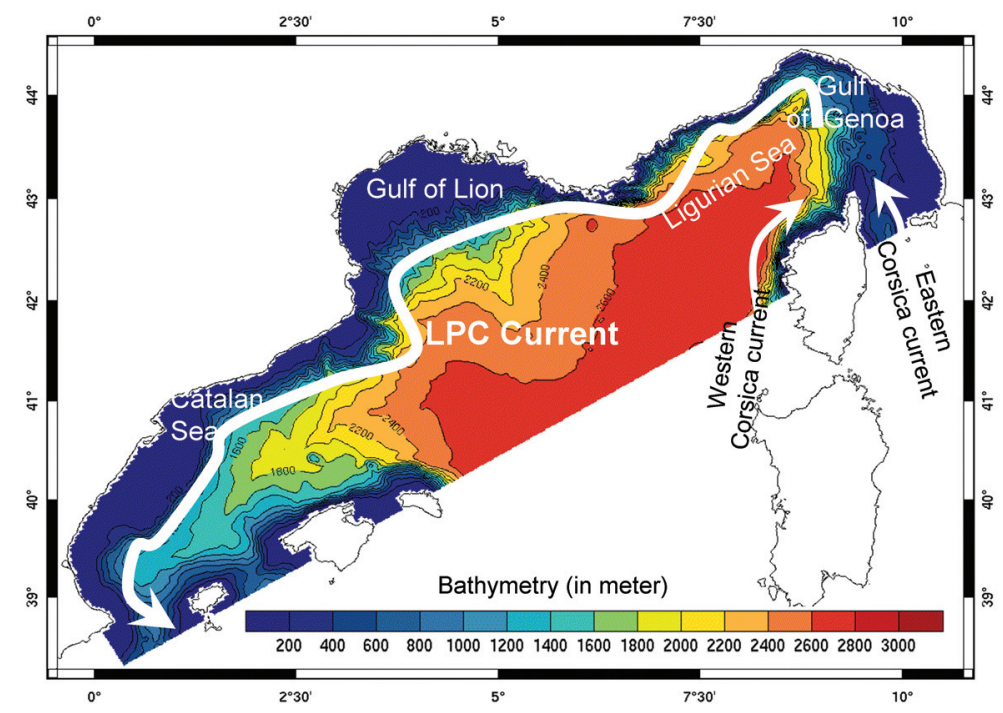

Fig. 1. Domain and Bathymetry of the study area. 
Banyuls (Guizien et al. 2006), dense-water formation over the continental shelf (Dufau-Julliand et al. 2004) and the circulation in the Catalan Sea (Jorda et al. 2006).

This model is based on the hydrostatic assumption and the Boussinesq approximation. An Arakawa C grid is used for the spatial discretization (Arakawa 1972). The horizontal grid is orthogonal, with a $3 \mathrm{~km}$ grid spacing 3.5 smaller than the Rossby deformation radius in the area; the model is eddy-resolving. A hybrid sigma-step coordinate system with 40 vertical levels is used. Figure 1 shows the modelled domain and bathymetry.

The advection scheme for temperature and salinity is a classic centred scheme (Arakawa and Suarez 1983). The horizontal viscosity is $30 \mathrm{~m}^{2} \mathrm{~s}^{-1}$. A free-slip lateral boundary condition is used and the bottom friction is quadratic. The free surface is calculated explicitly by decomposition of the model equations into internal and external modes as proposed by Blumberg and Mellor (1987). Vertical eddy viscosities and diffusivities are calculated according to the Gaspar et al. (1990) second-order closure scheme, with a prognostic equation for the turbulent kinetic energy and an algebraic formulation of the mixing and dissipation lengths. The external time step is $5.7 \mathrm{~s}$ and the internal time step is $229 \mathrm{~s}$.

Boundary conditions have a double role: they permit the radiation of outgoing waves and the forcing of the inner solution by external fields provided by a basin-scale model, here the MFSTEP general circulation model (Demirov and Pinardi 2002; Pinardi et al. 2003). This model is also based on the hydrostatic assumption and the Boussinesq approximation, but is eddy-permitting, with a $1 / 8^{\circ}$ resolution. As suggested by Blayo and Debreu (2005), this is achieved by applying our open boundary conditions schemes to the difference between the modelled and external variables rather than to the absolute variables. In practice, sea elevation and barotropic current are given by a Flather condition (Flather 1976), and the baroclinic velocities by a Sommerfeld type condition:

$$
\frac{\partial \Phi}{\partial t}+c \frac{\partial \Phi}{\partial n}=0
$$

Eq. (1) corresponds to the transport of the quantity $\Phi$ through the boundary $\Gamma$ where $n$ is the outward normal vector, with the velocity $c$. Temperature and salinity boundary conditions are specified by the advection scheme of the temperature and salinity equations so that external fields are advected into the numerical area under inflow conditions. The external field constraint is enforced by adding a restoring force to the equations in the vicinity of the lateral open boundaries. This restoring force is restricted to a 20 -gridpoint thick restoring boundary layer and decreases progressively with distance to the boundary. Details concerning the implementation of the open boundary conditions are given in Marsaleix et al. (2006). Initial and boundary conditions are provided at each time step by the time-interpolated biweekly averaged results of the basin-scale simulation performed with the general circulation model of the Mediterranean basin (Pinardi et al. 2003). At the surface, the model is forced by air-sea fluxes: heat flux (which is the resultant of the sensible, latent, and radiative fluxes), evaporation minus precipitation water flux and wind stress, computed using to the bulk formulae of Geernaert (1990). The freshwater discharges, principally those of the Ebro and Rhone rivers, are introduced as a lateral boundary condition (Estournel et al. 2001), using daily data provided by the "Confederación Hidrográfica del Ebro" and by the "Compagnie Nationale du Rhône".

There is a steric effect included in the model sea level anomalies but because of the Boussinesq approximation, its temporal variability is suppressed, and only its spatial structure remains. Greatbatch (1994) showed that sea level calculated by models making the Boussinesq approximation can be corrected for this problem by adjusting the model-computed sea level by a spatially uniform, but time dependent, constant that accounts for any net expansion/contraction of the global ocean. Since this correction is spatially uniform, it is not dynamically significant and does not affect the flow field calculated by the model. To compute this constant, we use the same method as Lombard et al. (2005). First, the reference density $\rho_{0}(x, y, z)$ is computed at each grid point using the classical expression for the equation of state of the ocean (Gill 1982) with the reference temperature $T_{0}=$ $0^{\circ} \mathrm{C}$ and the reference salinity $S_{0}=35.0 \mathrm{psu}$. This equation enables us to compute water density with a $3 \cdot 10^{-5}$ accuracy (Millero and Poisson 1981). At each time step $t$ the density $\rho(x, y, z, t)$ is also computed at each grid point using the same expression with the temperature $T(x, y, z, t)$ and the salinity $S(x, y, z, t)$. We then compute the spatial average of the steric effect over the modelled domain [Eq. (2)]:

$\operatorname{se}(t)=$ mean $_{\text {domain }}\left[\int_{-H}^{0} \frac{\rho_{0}(x, y, z)-\rho(x, y, z, t)}{\rho_{0}(x, y, z)} d z\right]$

We also compute the time-averaged steric effect over the whole simulation period [Eq. (3)]:

$\overline{s e}=$ mean $_{\text {domain }}\left[\int_{-H}^{0} \frac{\rho_{0}(x, y, z)-\overline{\rho(x, y, z)}}{\rho_{0}(x, y, z)} d z\right]$

We use the average density $\overline{\rho(t)}$ computed from the average temperature [Eq. (4)]:

$\overline{T(x, y, z)}=$ mean $_{\text {whole epriod }}[T(x, y, z, t)]$ 
and the average salinity [Eq. (5)]:

$\overline{S(x, y, z)}=$ mean $_{\text {whole period }}[S(x, y, z, t)]$

The correcting constant accounting for the net expansion of contraction of the global ocean at each time step is therefore $s e(t)-\overline{s e}$, which is then added to the model Sea Level Anomaly (hereafter SLA) data. In this way, the entire steric effect is included. The temperature and salinity fields used to compute the steric effect are taken from the general circulation model MFSTEP (Pinardi et al. 2003). Herrmann et al. (2008) indeed showed that the evolution on a global scale of the water characteristics in SYMPHONIE and in the general circulation forcing model are very close, the mean steric effect should therefore be similar in both models.

\subsection{The New Altimetry Processing Strategy}

The raw altimeter data used, are mostly based on the standard Geophysical Data Records (hereafter GDR) distributed by operational centres and made available with improved corrections by the Center for Topographic studies of the Oceans and Hydrosphere (hereafter $\mathrm{CTOH}$ ). These altimetry products include sensor measurements and a full set of geophysical and instrumental corrections necessary to compute altimetry elevations. In the deep ocean regions, the standard along-track $1 \mathrm{~Hz}$ observations in combination with standard corrections are in general sufficient to monitor ocean circulation. In coastal investigation studies, several data upgrades and new processing strategies have to be performed. Indeed, the coastal ocean reflects a very complex dynamic, being characterized by a wide range of short spatial and temporal scales, which are more difficult to observe with standard altimetry products. A coastal multisatellite altimetry dataset at $10 \mathrm{~Hz}$ (for TOPEX/Poseidon hereafter T/P and GFO) or at $20 \mathrm{~Hz}$ (for Jason 1 and Envisat) sampling rate has been derived from routine geophysical data products using a new processing software dedicated to coastal zone applications. Experiences gained from the ALBICOCCA project (Vignudelli et al. 2005) have been integrated in addition to an orbit and large-scale error reduction method. Table 1 summarizes the most important satellite characteristics and the main corrections which have been applied (for details refer to the AVISO user's Handbook 1996; GEOSAT Follow-On GDR User's Handbook 2002; AVISO and PODAAC user's Handbook 2004; the Envisat RA2/MWR Product Handbook)

The three following sub-sections highlight some important aspects of the new altimetry processing strategy for coastal regions, specifically the exploiting of higher alongtrack data rates, the adoption of improved de-aliasing procedures and the application of a method to minimize biases between the different missions.

\subsubsection{Improving the Along Track Spatial Resolution Using Higher Data Rates}

The $10 / 20 \mathrm{~Hz}$ altimeter data was generated - equivalent to a 580/350 m along track spacing - allowing capture of sea surface variability at smaller spatial scales than a standard $1 \mathrm{~Hz}$ sampling. Indeed, the local Rossby radius in the Northwestern Mediterranean Sea is about a few tens of kilometres and despite the low signal-to-noise ratio of the LPC, the characteristic length scales of energetic disturbances are of sufficient size and magnitude to be detectable with highresolution altimetry. As shown in Bouffard et al. (2006), the

Table1. Satellite characteristics and main corrections applied.

\begin{tabular}{|c|c|c|c|c|c|}
\hline Satellites & $\begin{array}{l}\text { Sampling/ } \\
\text { Period }\end{array}$ & $\begin{array}{l}\text { Sea Surface Bias } \\
\text { correction }\end{array}$ & Wet tropospheric & Ionospheric & $\begin{array}{l}\text { De-aliasing } \\
\text { (see } § 3.2 .2 \text { ) }\end{array}$ \\
\hline $\mathrm{T} / \mathrm{P}$ & $\begin{array}{l}10 \mathrm{~Hz} \\
10 \text { days }\end{array}$ & $\begin{array}{l}\text { Cnes Ku correction } \\
\text { (BM4) }\end{array}$ & $\begin{array}{l}\text { Radiometric } \\
\text { (on Ku band) }\end{array}$ & Dual frequency & $\begin{array}{l}\text { MOG2D } \\
\text { Medsea }\end{array}$ \\
\hline GFO & $\begin{array}{c}10 \mathrm{~Hz} \\
17.5 \text { days }\end{array}$ & $\begin{array}{c}\text { Non-parametric } \\
\text { (Labroue et al. 2004) }\end{array}$ & $\begin{array}{l}\text { Model wet tropo } \\
\text { NCEP }\end{array}$ & GIM model & $\begin{array}{l}\text { MOG2D } \\
\text { Medsea }\end{array}$ \\
\hline Jason 1 & $\begin{array}{l}20 \mathrm{~Hz} \\
10 \text { days }\end{array}$ & $\begin{array}{l}\text { Altimetric - GDR } \\
\text { (on Ku band) }\end{array}$ & $\begin{array}{l}\text { Radiometric } \\
\text { (on Ku band) }\end{array}$ & Dual frequency & $\begin{array}{l}\text { MOG2D } \\
\text { Medsea }\end{array}$ \\
\hline Envisat & $\begin{array}{l}20 \mathrm{~Hz} \\
35 \text { days }\end{array}$ & $\begin{array}{l}\text { Altimetric - GDR } \\
\text { (on Ku band) }\end{array}$ & $\begin{array}{l}\text { Radiometric } \\
\text { (on Ku band) }\end{array}$ & $\begin{array}{l}\text { Altimeter } \\
\text { (on } \mathrm{Ku} \text { ) }\end{array}$ & $\begin{array}{l}\text { MOG2D } \\
\text { Medsea }\end{array}$ \\
\hline
\end{tabular}


$10 / 20 \mathrm{~Hz}$ data exhibit the onset of white noise for scales of less than 3-km wavelength, whereas the smallest resolved scale for the $1 \mathrm{~Hz}$ data is about $12 \mathrm{~km}$. Given the fact that the oceanographic signal emerges from the noise level at scales larger than $3 \mathrm{~km}$, the $10 / 20 \mathrm{~Hz}$ along track data are then sub-sampled every $1.5 \mathrm{~km}$. Depending on the dynamic scales to be studied, the along-track Sea Level Anomalies are low-pass filtered using a Loess filter with cut-off windows at 5, 10, 60, and $100 \mathrm{~km}$.

\subsubsection{Reducing the Aliasing of High Frequency Signals in Altimeter Data Using Mog2d in a Regional Configuration}

In the coastal area, the sea surface variability due to atmospheric (wind and pressure) and tidal forcing represents a major source of errors which needs to be removed from the altimetric sea level observations for analysis purposes. These high-frequency barotropic signals are poorly resolved by the usual satellite repeat cycle, and are aliased into the altimetry signal, making the interpretation of baroclinic signals more difficult. The impact of the aliasing is worse for coastal regions because the high frequency signal is amplified in the coastal zone. While the wind effects are usually left uncorrected, the pressure effects are normally represented by the so-called Inverse Barometer (IB) correction, which is adequate for the open ocean, but known to be unsatisfactory in coastal and high latitude regions (Carrere and Lyard 2003). Ocean tide effects are usually corrected using global tide models that do not have sufficient resolution in the coastal regions. To counteract these effects, tides and ocean response to wind and atmospheric pressure forcing is computed using a regional hydrodynamic, barotropic model, called MOG2D-Medsea. It is characterized by a finite element spatial grid, which allows for increasing of the resolution in regions of interest, such as high topographic gradient areas and shallow waters, where most of the bottom friction dissipation occurs. Contrarily to the global configuration used for standard altimetric applications, MOG2D has been implemented in a regional configuration with finer grid elements, which allows a better correction of the altimetric signal from the small spatial scale barotropic high frequency dynamics.

\subsubsection{Adopting a Large-Scale Error Reduction Method}

Taking advantage of multiple satellite sources does not necessarily improve the quality of the final product because of inter-mission biases. Even if MOG2D-Medsea is consistently used to de-alias time series from all the altimetric missions, the effect of heterogeneous corrections and errors between the various missions would be difficult to assess. This is especially the case for the large-scale errors due to orbits.
There are a number of orbit estimation techniques that can be used to remove the predominantly sinusoidal orbit error. The choice of technique will depend on the scales of variability that are to be resolved. Over short distances, the orbit error can be modelled by a polynomial approximation; generally a first order bias and tilt fit for arc lengths smaller than $1500 \mathrm{~km}$ (as it is the case over our study area), or by a quadratic fit for arc lengths larger than $2500 \mathrm{~km}$ (e.g., Cheney et al. 1983; Zlotnicki et al. 1989). The balance between the different polynomial approximations of orbit error and overfitting of the data has been investigated for different arc lengths by Tai $(1989,1991)$ and compared with the sinusoidal orbit model by Van Gysen et al. (1992). The short arc polynomial fit has shown to be useful for regional studies, whereas the long-arc sinusoidal method is preferred for basin-scale variability. So, in our case study orbit outliers are corrected using a bias adjustment over the length of the altimetric tracks. In order to validate the method, we have checked the standard deviations of the SLA differences at the single crossover points. The standard deviation has been calculated with and without the large-scale error reduction procedure. The standard deviation of the SLA differences at the single crossovers is the same for T/P, Jason and Envisat with and without the large-scale error reduction procedure (respectively 4.2, 3.6, and $5.5 \mathrm{~cm}$ ). T/P and Jason exhibit minimum STD at crossover points, with and without the large-scale algorithm. This is due to the good accuracy in the orbit determination (better than $2.5 \mathrm{~cm}$, Ries and Tapley 1999). On the contrary, GFO shows a large scale noise reduction with a decrease of the SLA differences standard deviation of $2.4 \mathrm{~cm}$ (from 8.7 to $6.3 \mathrm{~cm}$ ).

\subsubsection{Comparison of the Improved Coastal Altimetric Dataset with Standard AVISO Product and Vali- dation with Tide Gauge Measurements}

In order to validate the altimetric coastal data processed with the new software targeted to coastal applications, the generated product and a standard distributed regional product were intercompared with tide gauges. The standard product is an along-track SLA product especially adapted to regional studies over the Mediterranean Sea [Delayed Time-(M)SLA "Update", handbook SSALTO/DUACS 2006] and made available by AVISO. Specific algorithms and corrections have been developed to improve the quality of this regional altimetric data product. The comparison, which deals with the quality and quantity of altimetric SLA, shows significant differences (number of data in coastal zone, correlation with tide gauge records, along track anomalies structures). This example focuses on track 9 of T/P and the Monaco tide gauge. Figure 2 shows the number of along-track altimetric data available between 07/01/1999 and 07/01/2002 (maximum common period between the T/P and the Monaco tide gauge measurements). From this picture, it follows that the 


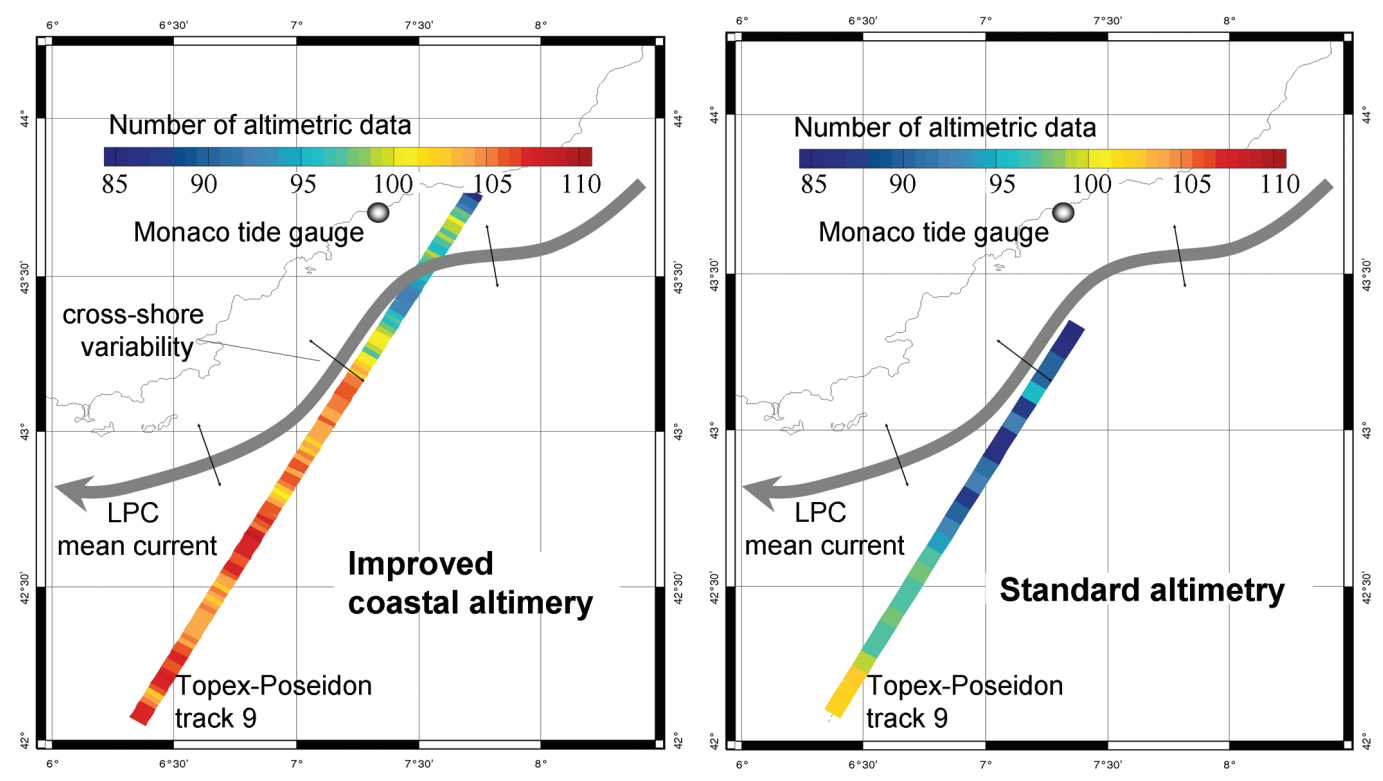

Fig. 2. Number of T/P track-9 data available between 07/01/1999 and 07/01/2002 close to the Monaco tide gauge and LPC current mean.

new processing method allows for recovering more data both far from and near to the coast. The improved coastal altimetry time series are about $10 \%$ longer compared with the standard product. Moreover, improved coastal data go closer to the coast, which is very helpful to detect the LPC dynamics.

These previous results can be explained by the use of the high frequency along-track sampling in addition to suitable quality control procedures.

Figure 3 shows the along-track percentage of Monaco tide gauge Root Mean Square (hereafter RMS) explained by altimetry time series. The higher the percentage, the higher the consistency between the altimetry and the tide gauge measurements. According to Fig. 3, the percentages are significantly higher with the improved coastal altimetry than with the standard altimetry over the whole T/P track. This is the case at the point of maximum percentage of explained RMS (see the curves at the bottom of Fig. 3) about $38 \%$ and $31 \%$, respectively for the improved coastal altimetry and for the standard altimetry. There, the correlations between the tide gauge and altimetry are also higher for the improved coastal altimetry than for the standard altimetry (0.79 against 0.72 ). The RMS difference between the lowpass filtered (with a window cut-off of 30 days) altimetry and tide gauge signals is equal to $2.5 \mathrm{~cm}$ for the improved coastal altimetry and $3.2 \mathrm{~cm}$ for the standard product.

Similar inter-comparisons have been done with the other tracks and satellites in the neighbourhood of 20 tide gauges located along the North-western Mediterranean coast. The results are equivalent and show a better consistency between the tide gauges and the improved coastal altimetry than with the Delayed Time-(M)SLA "Update" product.
On average over the whole set of available tide gauges, the RMS difference between improved altimetry and tide gauge instantaneous signals are between 4.1 and $3.9 \mathrm{~cm}$ for the 4 satellites used. The same statistics made with the low-pass filtered signals (window cut-off of a 3-altimetric repeat period) show an RMS difference about $2.9 \mathrm{~cm}$ for all the altimetric missions. This represents a qualitative improvement between $7 \%$ and $10 \%$ compared with standard altimetry.

Moreover, the data processed, using the new method, are able to detect smaller dynamical processes and to come closer to the coast than the ones observed with standard altimetry. Lastly, the new processing method allows recovery of an additional $10 \%$ of the available coastal data. Such data can be useful in order to monitor the LPC dynamics and small-scale coastal processes. Therefore, they are more adequate for validating a regional model implemented in the North-western Mediterranean than standard distributed data.

\subsection{Generation of a Homogeneous Boussinesq Model/ Altimeter Dataset}

SYMPHONIE is a Boussinesq model whose mathematic approximations entail restrictions on the study of certain oceanic processes. The most important component of sea surface variability observed by altimetry is the steric sea level change due to expansion/contraction associated with net heat fluxes into the ocean on seasonal and longer time scales. Boussinesq kinematics conserves the volume, rather than mass of the global ocean. Therefore, it does not reproduce the low-frequency steric signal. In this study, the mass conservation problem in the Boussinesq model is cor- 


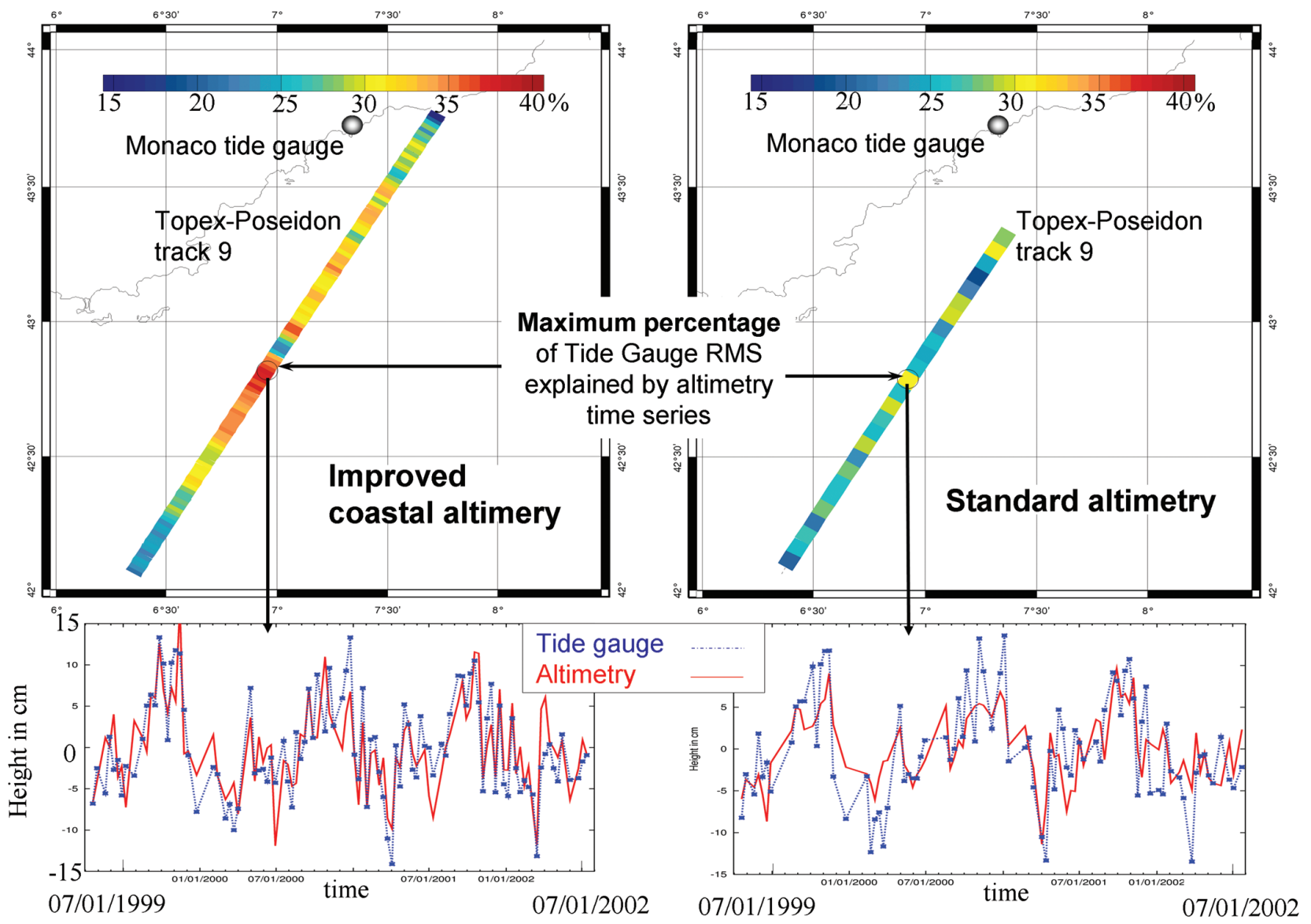

Fig. 3. Along-track percentage of Monaco tide gauge explained by altimetry time series (top) and altimetric vs tide gauge time series at the point of maximum percentage (bottom).

rected by adding a spatially uniform value that evolves in time, as explained in section 3.1. The explicit inclusion of these non-Boussinesq effects in the SYMPHONIE model results facilitates the direct comparison between sea levels computed by the model and observed from altimetry.

Another problem in terms of altimetry/SYMPHONIE homogeneity is the marine geoid as a reference level. Since the marine geoid is not known with sufficient spatial accuracy, the Mean Sea Level (hereafter MSL) is removed from the Sea Surface Height (hereafter SSH) along each satellite track to compute the SLA. Care should be taken to have consistent SLA for the different altimetric missions. First, the MSL is calculated over the longest time period for each ground track of each altimetric mission. The model MSL is also calculated over the period 2001 - 2003 and removed from the SYMPHONIE elevations. Then, for the intercomparisons between altimetry and SYMPHONIE, an additional mean is removed both in the altimetric data and in the model over the common time period. This allows comparison of the along-track sea level variability from the model with the one from the altimeter data. Both model and altimetry SLA have been linearly interpolated on common along track ref- erence grids sampled every $1.5 \mathrm{~km}$. The along track SLA are then low-pass filtered using a Loess filter with cut-off windows at $5 \mathrm{~km}(60 \mathrm{~km}$ in section 4.1.2).

The main difficulty in comparing the model and altimetry SLA is due to the fact that in the North-western Mediterranean $\mathrm{Sea}$ - and especially around the LPC - the oceanic circulation is dominated by mean circulation. The amplitude of the sea surface variability is small and characterised by a wide range of temporal and spatial scales, which are difficult to observe with altimetry. It is also a challenging issue to correctly simulate 3-D oceanic circulation variability in coastal areas where the mesoscale and sub-mesoscale components often seem to be chaotic. As noted in Send et al. (1999) the complexity of small spatial scales and intense gradients interacting with small temporal scales make the understanding and modelling of oceanic dynamics in the Western Mediterranean particularly difficult.

As specified in the previous section, barotropic dynamics due to wind effects have been removed from the altimetric signal whereas the SYMPHONIE model reproduces such a dynamic. Even if this could be a small source of nonhomogeneity between the model and the altimetric data, it 
allows removal of gravity waves propagating from outside the model boundaries and entering inside the SYMPHONIE domain. These gravity waves are not simulated by the rigidlid MFSTEP-OGCM and thus cannot be propagated inside the SYMPHONIE model.

\section{RESULTS: INTERCOMPARISON SYMPHONIE VERSUS ALTIMETRY}

This section aims to compare the sea surface variability observed by the coastal multi-satellite altimetry data with the dynamic topography from the SYMPHONIE model. The SYMPHONIE elevations are computed from January 2001 to December 2003. Several diagnostics are used to compare the model and the altimetry SLA in space and time. The altimetry data used during this period are as follows: from January to December 2001, SLA was computed using the T/P original orbit data and GFO data. From January to December 2002, SLA was computed using Jason-1 and GFO data. From January to December 2003, the SLA was computed using Jason-1 (along the T/P old orbit), GFO and Envisat data.

\subsection{Spatial Comparisons}

\subsubsection{Regional Average of Model-Data Correlations}

We first assess how well the SYMPHONIE model reproduces the observed satellite altimetry SLA along each altimetric pass. The along-track correlations between each altimetric pass and its equivalent model SLA are then computed over the whole SYMPHONIE domain and for each altimetric cycle (see Fig. 4). Within the SYMPHONIE domain, about 240 GFO satellite passes, 304 T/P and Jason-1 passes and 220 Envisat passes are available each year.

Figures 5 to 7 show the statistical distributions of the altimetry/model correlations from three different altimetric missions and for three different years: 2001, 2002, and 2003. These figures only refer to the zero-lag (in space and time) correlation of the height anomalies. Thus, a small dephasing in time or a small spatial shift in the dynamical structures can significantly reduce the correlations.

According to Fig. 5, more than $50 \%$ of along-track correlations between SYMPHONIE and T/P SLA are greater than 0.2 and $35 \%$ are greater than 0.4 . These values are significant at the $99 \%$ level given the large number of tracks and independent along-track points included in the correlation calculations. It should be noted that we compare the variabilities of the sea level and not the total dynamic topography which also includes the mean circulation. In 2002, the results of GFO (see Fig. 6) and Jason-1 are similar to those observed in 2001. In 2003 the Jason-1 correlations with the model are weak (see Fig. 7) with only $2 \%$ of the correlations greater than 0.4. This difference between the altimetric and the model SLA in 2003 is most likely due to problems with

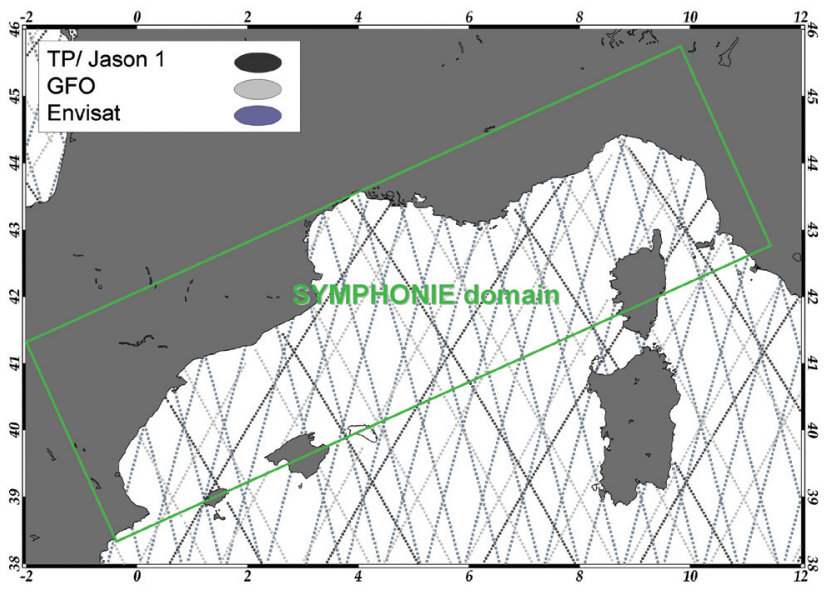

Fig. 4. Satellite ground tracks used over the SYMPHONIE domain.

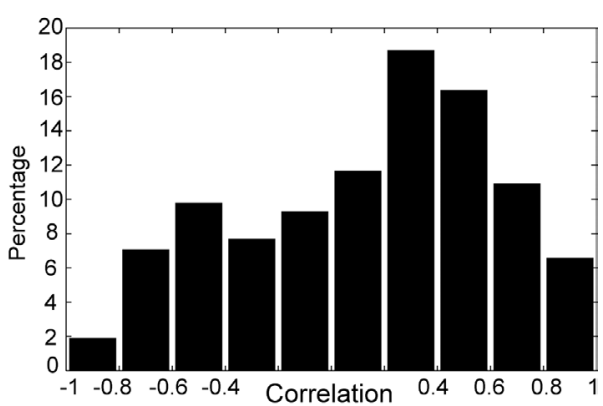

Fig. 5. Statistical distribution of along track correlations between T/P SLA and SYMPHONIE model SLA (from January to December 2001).

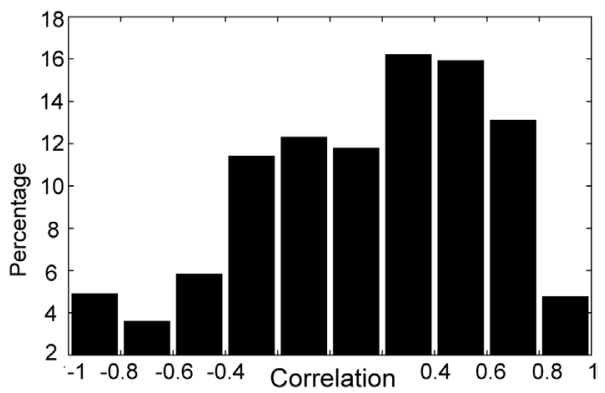

Fig. 6. Statistical distribution of along track correlations between GFO SLA and SYMPHONIE model SLA (from January to December 2002).

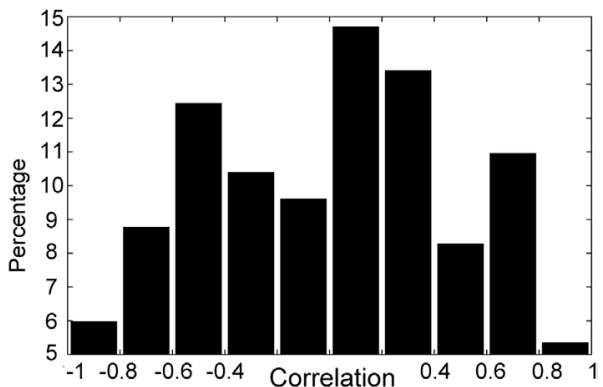

Fig. 7. Statistical distribution of along track correlations between Jason SLA and SYMPHONIE model SLA (from January to December 2003). 
the model boundary conditions during some months, which may entail problems in the mesoscale dynamics simulation. This boundary condition problem will be adressed at the end of section 4.2.

To summarize, these statistical results dominated by the instantaneous small spatial dynamic scales are encouraging, because the correlations are significant and calculated between two spatial sea levels from which the mean circulation has been removed (refer to section 3.3). In this respect, the permanent cross-shore positive slope-due to the geostrophic balance part of the LPC current-is not taken into account for the correlation calculations. Thus, this makes the comparisons particularly difficult because the along track signal is then essentially influenced by mesoscale and sub-mesoscale dynamics. In addition to the previous statistical results, it is also necessary to explore qualitatively some along-track comparisons.

\subsubsection{Case Studies: Some Examples}

This section focuses on five synoptic altimetric tracks which cross the LPC current (see Fig. 8) in order to evaluate the potential agreement between the altimetric and model along track SLA.

Figure 9 shows the SYMPHONIE model and the coastal processed altimetric SLA data extracted along the five altimetric ground tracks as a function of latitude and during the end of May and the beginning of June 2002.

Figure 9 shows the good agreement between the mesoscale altimetry and model SLA (correlation between 0.6 and 0.9). The slopes are well represented in the model and the small spatial structures are almost perfectly in phase. However, in this example there is also an offset of about $7 \mathrm{~cm}$ between the model and the altimetry observations. This bias is observed with two independent altimetry datasets (GFO and Jason), so this explains that it is not a residual orbit error in the altimetric data. This bias may be due to an

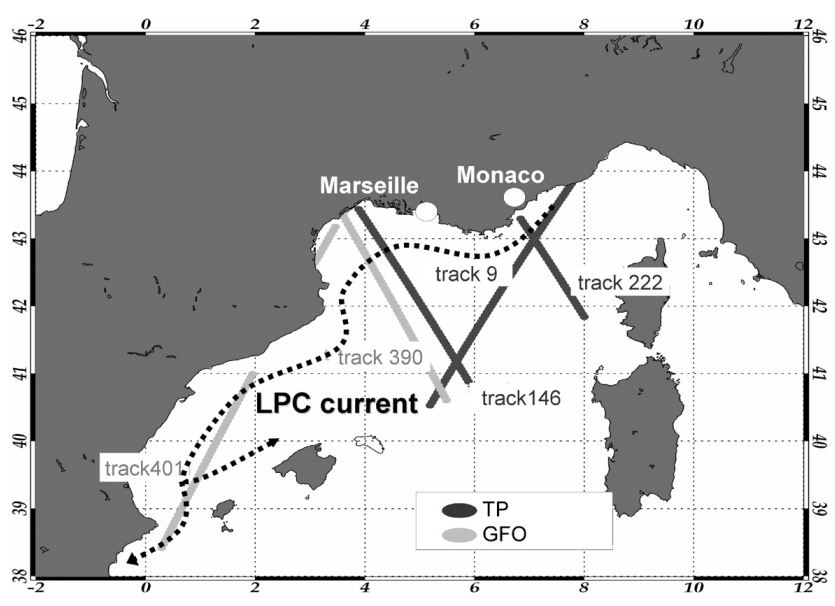

Fig. 8. Ground track locations and approximate position of the LPC. error in the computation of the mean steric effect.

In the next section, we will compare the temporal evolution of the altimetric and model SLA along-track average. This will allow us to check how often that bias appears or if the SYMPHONIE model combined with the computed
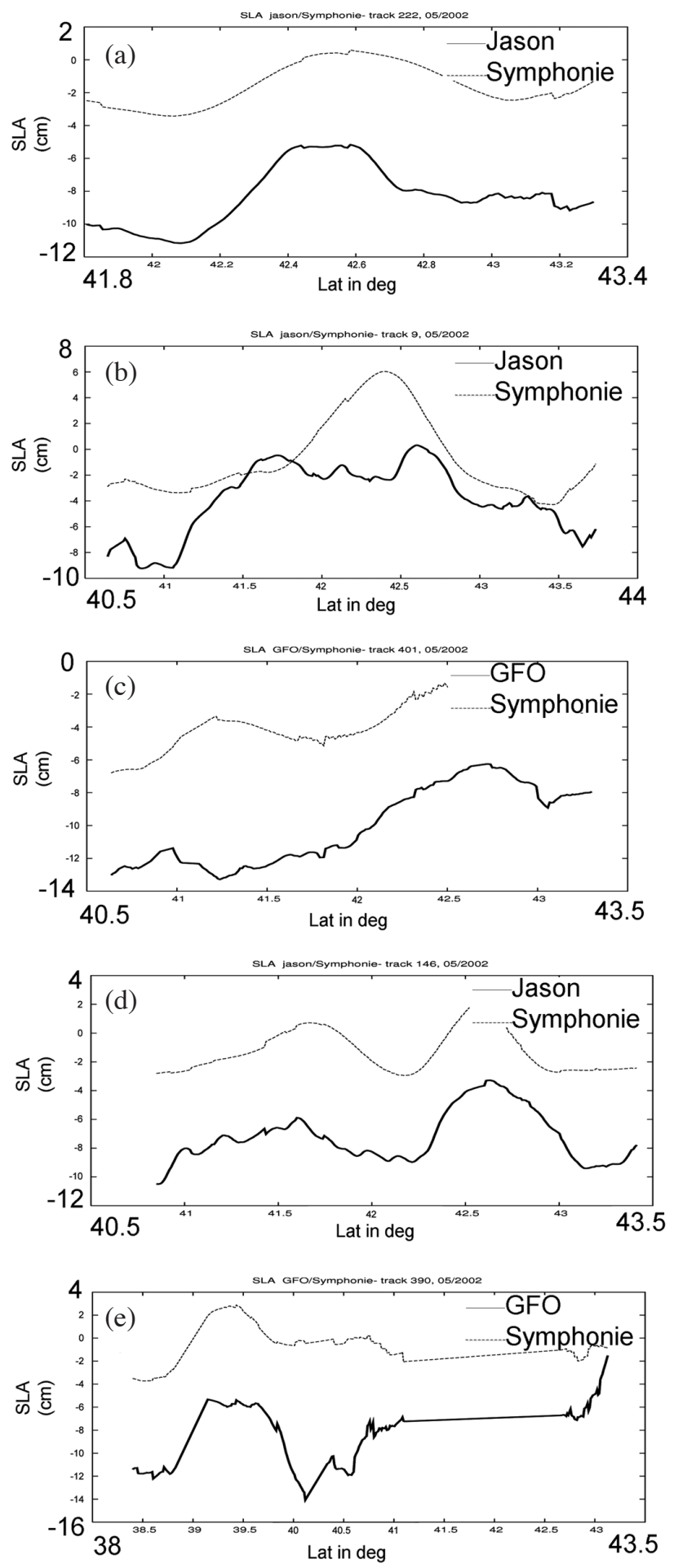

Fig. 9. Along-track SLA altimetry vs SLA model / Latitude May - June 2002, (a) Jason track 222; (b) Jason track 9; (c) GFO track 401; (d) Jason track 146 and (e) GFO track 390. 
steric effect (see section 2.1) is able to reproduce well the large wavelength temporal evolution.

\subsubsection{Time Evolution of the SLA at Large Wavelengths: T/P Track 146}

This section focuses on the T/P track 146 (see Fig. 8) from January 2001 to December 2003 in order to study the time evolution of the large spatial scale features of the model and altimetry data. The temporal evolution of the alongtrack altimetric and model average SLA is computed in Fig. 10.

The temporal evolution (Fig. 10) shows that there is indeed a bias between the model and the altimetry, which occurs at the beginning of June 2002; however, such a bias is rare and clearly evolves in a random way over time. In general, Fig. 10 shows good agreement between the temporal evolution of the model and the altimetric SLA averages. The annual cycle is well represented in both datasets with similar shapes and equivalent amplitudes in both the model and altimetry. These low frequency large-wavelength signals are essentially due to net heat fluxes into the ocean on seasonal and longer term time scales. Thus, the coherence between the model and the altimetric signal partially validates the method used to simulate the low frequency steric component.

Concerning the temporal evolution of the SLA standard deviation (bottom right side of Fig. 10), there is a good coherence in terms of time evolution. However, the SLA standard deviation amplitudes in the model are often lower than in altimetry. This can be due to an underestimation of the SLA variability in the model. On closer scrutiny, the maximum of SLA standard deviation in altimetry appears between July and December. This maximum is particularly well identified in 2001, and partially well reproduced by the model. It is not surprising, given that Gostan (1967) and

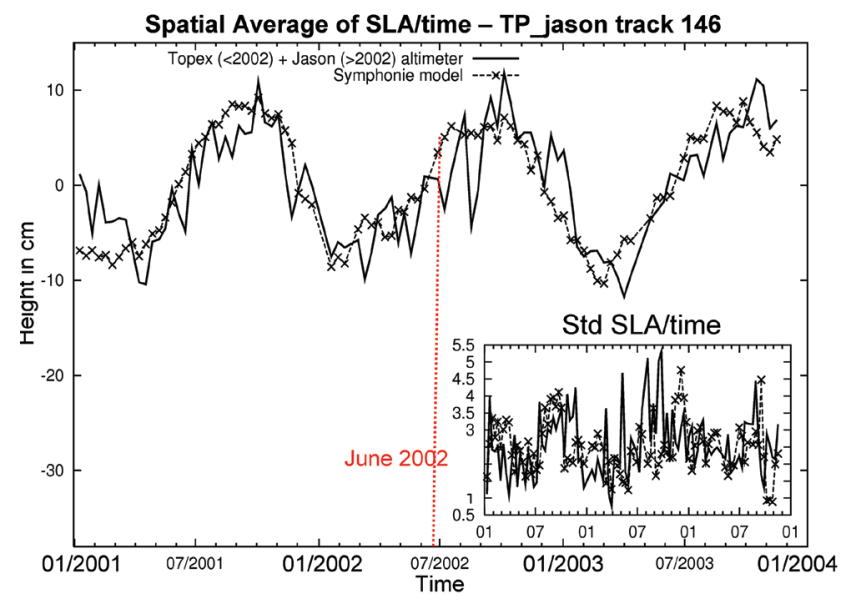

Fig. 10. Time variability of the large spatial scale: T/P + Jason track 146 vs. SYMPHONIE model (From January 2001 to December 2003).
Millot (1987) show that the LPC is strongly marked by a seasonal variability (see Section 1): from June to December the LPC enlarges and slows down which induces an alongtrack anomalies negative slope; the LPC is a density-driven current, which is essentially geostrophic. In these hypotheses, the large-scale gradient of the sea surface topography (mean circulation + SLA) between the open ocean and the continental slope is always positive. When the current intensity decreases, this gradient decreases and thus the slope of the SLA becomes negative. These large wavelength negative slopes are one of the reasons why the spatial along-track standard deviation is maximum from June to December. The following figures show an example of a SLA model and T/P along track 146 during the standard deviation maximum in September 2001 and just before the current slows down in June 2001 (Fig. 11).

\subsubsection{Time Evolution of Spatial Correlations between the Altimetry SLA and the SYMPHONIE Model Sea Surface Height}

Here we analyse the time evolution of along track correlations between the altimetry and the SYMPHONIE model from January 2001 to December 2003 for the track 146. The objective of this section is to identify if there are certain seasons or years where the model SLA is close to the altimetric observations, or if the differences are quite random.

T/P-Jason track 146 (Fig. 12) shows good results most of the time, especially in 2001 with a mean correlation of 0.5. However, from February to March (2001 and 2003) correlations are lower; this happens also from May to July 2003. The same work has been done over all the available altimetric tracks and clearly shows that the results are less good in 2003, which can be explained by problems in the boundary conditions of the model. Complementary explanations will be developed at the end of Section 4.2.

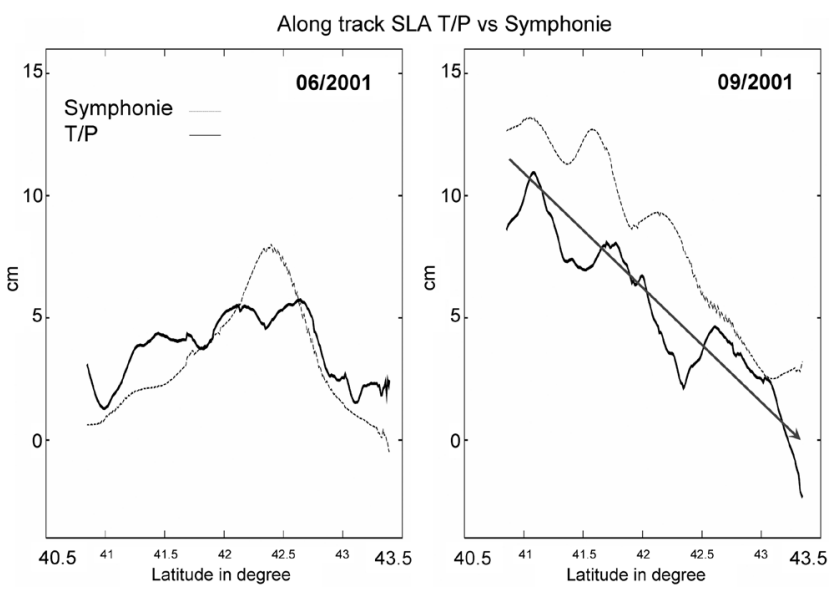

Fig. 11. SLA T/P SYMPHONIE, track 146 (left: 06/2001, right 09/2001). 


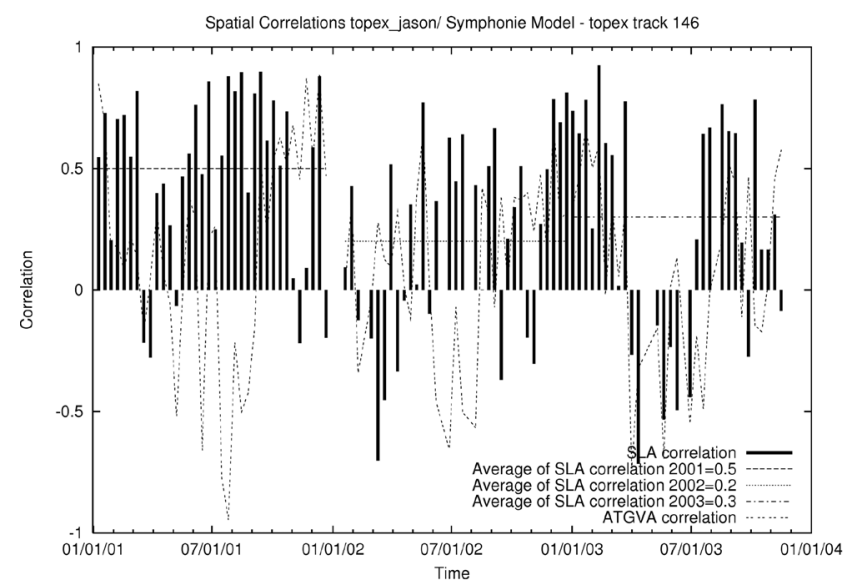

Fig. 12. Time evolution of the along track spatial correlations: T/P + Jason track 146 vs. SYMPHONIE model (From January 2001 to December 2003).

The next step is to identify and localize where the model and the altimetry observations are coherent, and on which spatial and temporal scales there are agreements and disagreements.

\subsection{Temporal Comparisons}

\subsubsection{Statistical Results over the Whole SYMPHONIE Domain}

Figures 13 to 16 show the along-track correlations per year between the altimetry SLA and the SYMPHONIE SLA time series. Although the number of passes per year varies between the different altimetry missions (because of different satellite repeat periods), we have computed the multi-satellite correlations on the same figure. This allows achievement of a better coverage of the area and thus highlights regions of good and bad correlations. It is important to note the good coherence at multi-satellite crossover points (Figs. 13 to 15). SLA on an ascending and a descending track are not sampled at the same time, with the same consistency, and not always with the same satellite. However, the correlations often have a close value, which gives us confidence of the robustness of the altimetry processing in addition to the statistical methodology.

The correlation maps show higher values at a certain distance, far from the continental shelf. In 2001 (Fig. 13), the offshore correlations are higher than 0.7. Results are not as good close to the coast, along the continental slopes (especially between Marseille and the Gulf of Genoa) and over the Gulf of Lions. In 2002 (Fig. 14) the results are similar but with lower correlations, in particular in the southern Catalan Sea and in the Ligurian Sea. In 2003 (Fig. 15), the scores are similar to those in 2001 but with a better spatial coverage of altimetry due to the Envisat data. However, poor correlations are again localized in the Ligurian Sea along the continental slope, in the southern Catalan Sea and in the west of the Gulf of Lions.

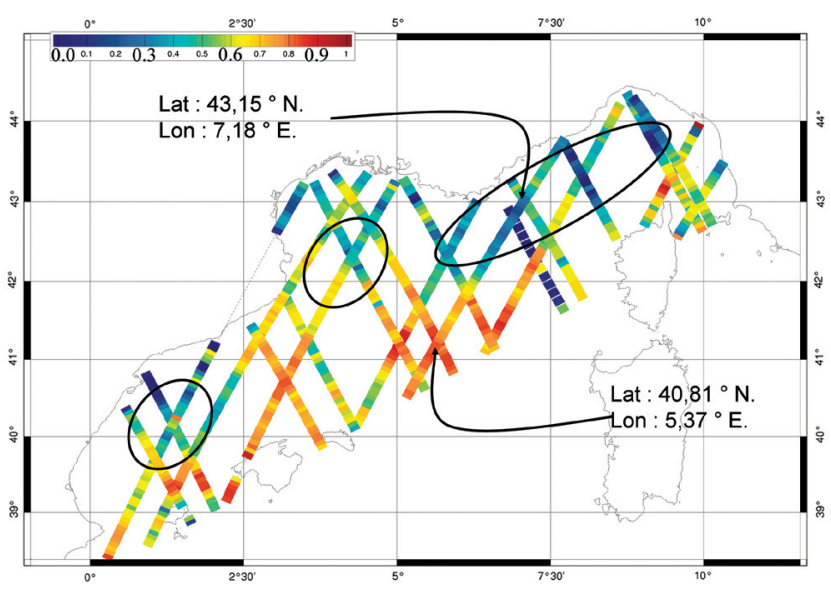

Fig. 13. Correlation between the T/P + GFO sea level variability and the SYMPHONIE model elevations - 2001.

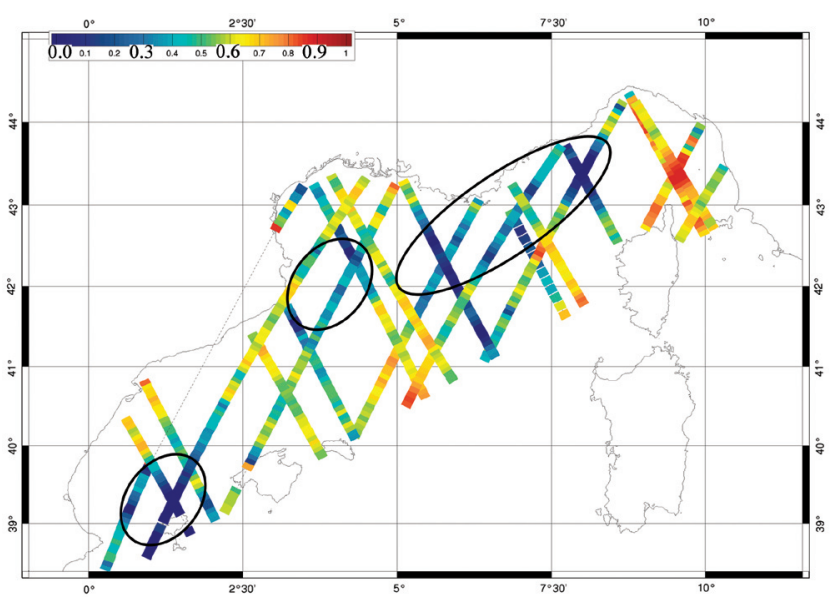

Fig. 14. Correlation between the T/P + GFO sea level variability and the SYMPHONIE model elevations - 2002.

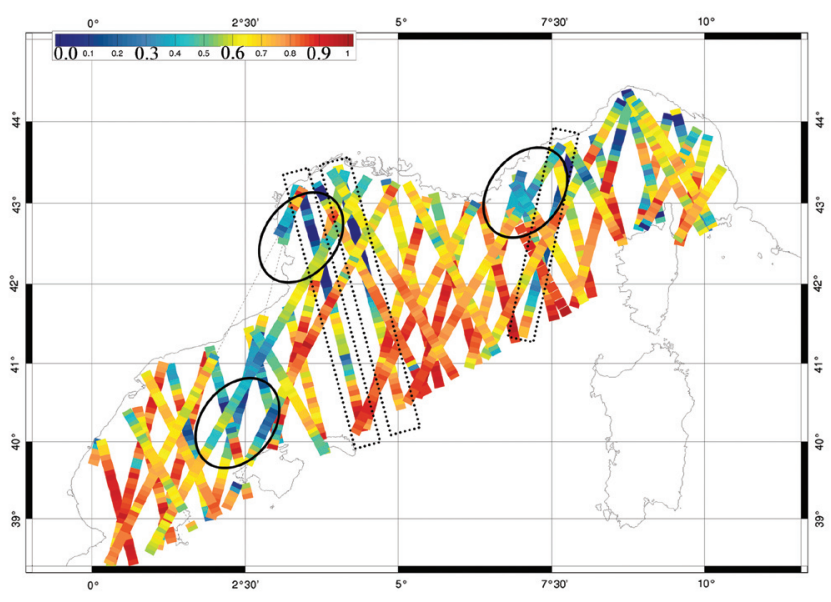

Fig. 15. Correlation between the T/P + GFO + Envisat sea level variability and the SYMPHONIE model elevations - 2003. 
The model and altimetric data are different in some areas. Those disagreements can be due to a number of reasons.

Firstly, close to the coast area altimeter, data can be affected by land contamination in the altimeter footprints, which strongly depends on the coastline geographic configuration (Deng et al 2002). In addition, corrections based on microwave radiometer measurements, with an even larger footprint, are also contaminated when the altimeter approaches or leaves the coast.

Moreover, the altimetric data can be affected by residual large-scale errors concerning a minority of satellite tracks (see Fig. 15, tracks in the dashed rectangles). The latter are easily localized because of bad statistics along the whole altimetry track. These errors are detected by large offset at crossover points and are mainly due to a bad orbit determination.

The LPC is a cyclonic along-slope density current characterized by a wide spectrum of spatial and temporal scales of variability. The coastal current does not always follow the coastline. The coastline irregularities disturb the LPC flow and induce a complete change in its dynamic properties. The mean kinetic energy is dissipated in turbulent energy where the current becomes unstable. These instabilities occur along the continental slopes and evolve into very energetic filaments and eddy structures. Even if the SYMPHONIE model is able to reproduce such sub-mesoscale dynamics, it is very difficult to simulate it at a given time and at the very precise location intercepted by the altimetric track. La Violette (1990) has shown that a large variety of mesoscale features interacts with the basin circulation. Indeed, on space scales close to the width of the current, instabilities can deeply modify the structure of the current. The baroclinic instability is the most important mechanism associated with mesoscale dynamics along the continental slope. Pedlosky (1979) gives a simple explanation show-

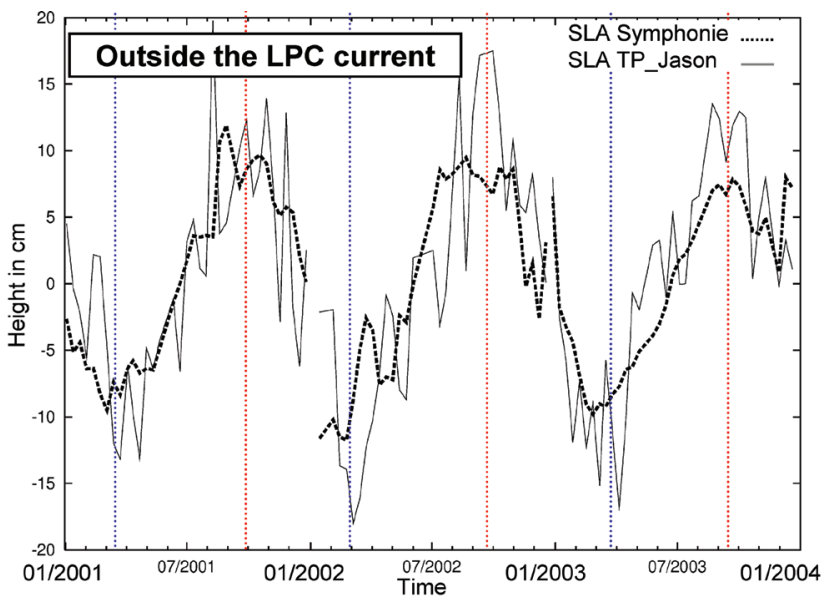

Fig. 16. SLA at 40.81 deg. in Latitude, 5,37 deg. in Longitude (2001/ 2003). ing that it corresponds to instabilities due to the sloping isopycnals. These slopes result from the vertical shear of the current velocities, which becomes important in this region as the current interacts with subsurface canyons along the continental slopes. The sea surface signature of such mesoscale and sub-mesoscale dynamics could explain the disagreements between model and altimetry SLA around the LPC. The model is able to reproduce realistic small mesoscale variability. However, any small spatial or temporal dephasing between model outputs and the altimetry measurements will produce a low zero-lag correlation between both time series. This could explain poor statistics (see the circles Figs. 13 to 15) in some areas where the sub surface topography is known to generate baroclinic instabilities (see Millot 1991).

\subsubsection{Focus on Two Particular Areas}

Figures 16 and 17 show the model and T/P-Jason SLA time series far from the LPC and in the heart of the LPC, respectively, along T/P-Jason track 9 (see Fig. 13 for the locations). Figure 16 exhibits a good agreement between the model and the altimetric time series. Both signals are well phased but the altimetry shows higher amplitude in the SLA time series. Inside the LPC (Fig. 17) both signals have a similar shape but they are out of phase. Moreover, the seasonal signal has lower amplitude within the LPC (Fig. 17) than in the deep ocean (Fig. 16) which is evident in both the altimetry and the SYMPHONIE model along T/P track 9. This is also true at other places near the Ligurian Sea. Given that the same low frequency steric signal is applied over the whole domain of the model, it is assumed that the differences are mainly due to the specific seasonal dynamics of the LPC.

In addition to offsets due to mesoscale and sub-mesoscale features, there can be delays between the maximum

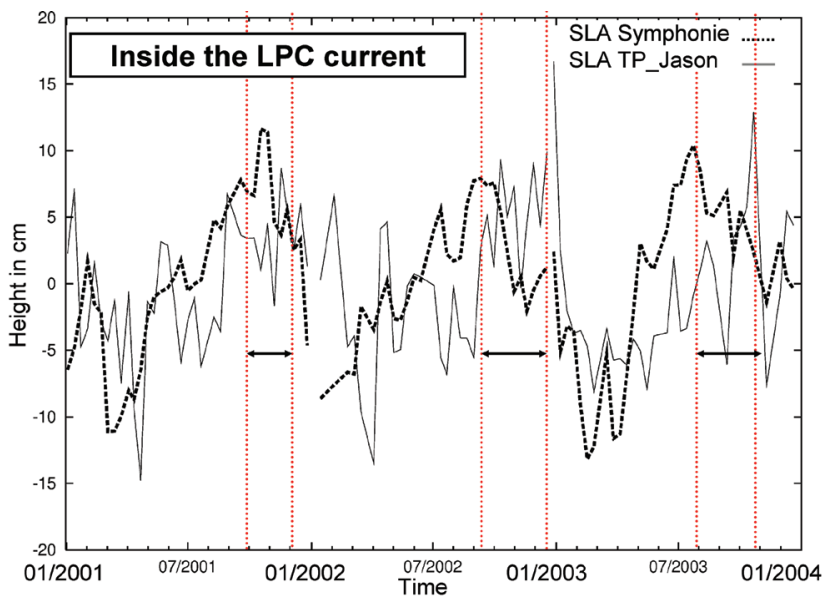

Fig. 17. SLA at 43.15 deg. in Latitude, 7,18 deg. in Longitude (2001/ 2003). 
(and minimum) of the model SLA and the altimetry SLA, with the altimetry signal usually leading the model SLA. These temporal lags occur near the coast, in the LPC coastal current that flows across the Ligurian Sea and into the Gulf of Lions. These are responsible for the weakening of correlations (between 0.1 and 0.4 ) between the model and the altimetry SLA even if the shape and the amplitudes of both time series are often similar. As noted in section 2, the LPC is characterized by a strong seasonal variability. On a seasonal scale, the low frequency component of the steric effect also entails a sea surface signature in the altimetry time series. As shown in section 3.1.3 there is a very good agreement concerning this seasonal signal between the altimetry and model at the spatial scale of an altimetry ground track. However, on closer consideration, the seasonal signal is different around the LPC, which suggests there is a nonsteric seasonal variability of the coastal current. It has long been realized that the variability of sea level height at tide gauges on the coast is different from the steric height of the deep ocean not far offshore (Pattullo et al. 1955). Using tide gauges at Newport, Oregon and Neah Bay, Washington, Reid and Mantyla (1976) perfected a method of extending the calculation of steric height (relative to a deep reference level) over the much shallower slope and shelf to within 5 $\mathrm{km}$ of the coast. Use of this method reveals that changes in sea level at the coastal tide gauges are controlled by the cross-shelf geostrophic slopes in the SSH associated with narrow jets found over the shelf equatorward in summer and poleward in winter (Huyer 1990). By extending the deep ocean steric height signals over the shelf, Reid and Mantyla made possible a more realistic resolution of these shelf circulation features by hydrographic measurements.

In order to highlight the relative role of the steric effect and the LPC seasonal variability, the low frequency steric signal computed (see section 2.1) has been removed both in the altimetry and model SLA (Figs. 18, 19).

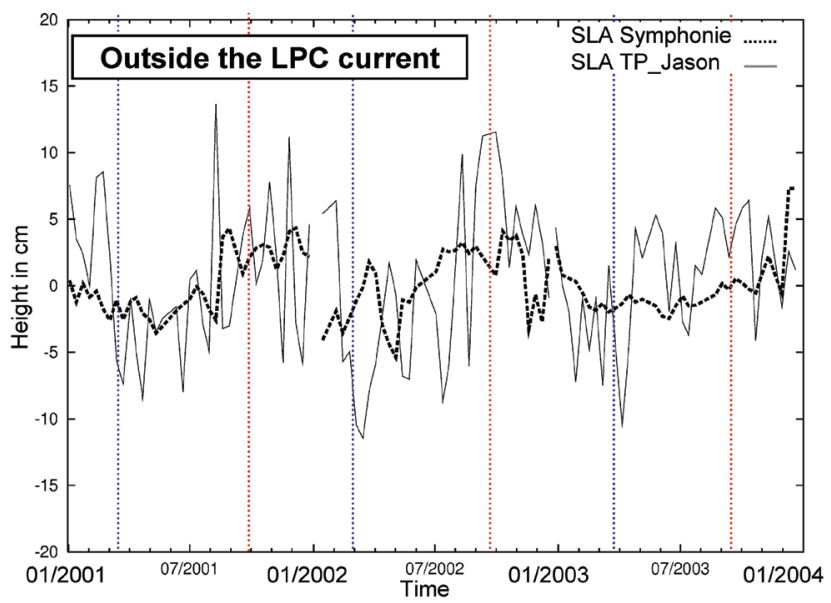

Fig. 18. SLA minus steric effect at $40.81 \mathrm{deg}$. in Latitude, 5,37 deg. in Longitude.
By removing the low frequency steric signal in both the altimetry and the model, the amplitude decreases by a factor of 3 . It is noted that the residual seasonal variability exhibits a very good agreement between the model and altimetry far from the LPC (Fig. 18). The low frequency component of this residual signal is due to a local steric signal, with minimum amplitude in April and a maximum in September.

Inside the LPC coastal current (Fig. 19), a seasonal signal is also clearly observed both in altimetry and model data. It is interesting to note that the amplitudes of this signal are significantly more important in the altimetry than in the model whereas this is not the case in the deep ocean. Thus, the slope between the coast and the deep ocean is underestimated in the model. In a geostrophic hypothesis, this allows for the conclusion that the variability of the coastal current along the LPC is also underestimated in the model. Moreover, the signal inside the LPC current is out of phase with the residual steric signal previously observed far from the LPC. The minimum of this seasonal non-steric signal occurs during summer (July - August) every year both in the model and the altimetry data. The maximum occurs in winter, but the model maximum often precedes the altimetric maximum by a few months.

From October 2002 to July 2003, the model does not show the same seasonal LPC cycle as altimetry, and the model seems less realistic in its representation of the LPC dynamics (see Fig. 19). This disagreement appears to be related to the external forcing terms of the open boundary conditions, prescribed by the general circulation model MFSTEP. To check it, we compute the transport of the MFSTEP-OGCM at the Corsica channel boundary condition and we compare it with transport computed from in situ data (Vignudelli et al. 2000) at the same location (see Fig. 20).

Figure 20 shows that the in-situ transport and the MFSTEP transport are well-phased until October 2002. Even if during this period, the MFSTEP transport is stronger about

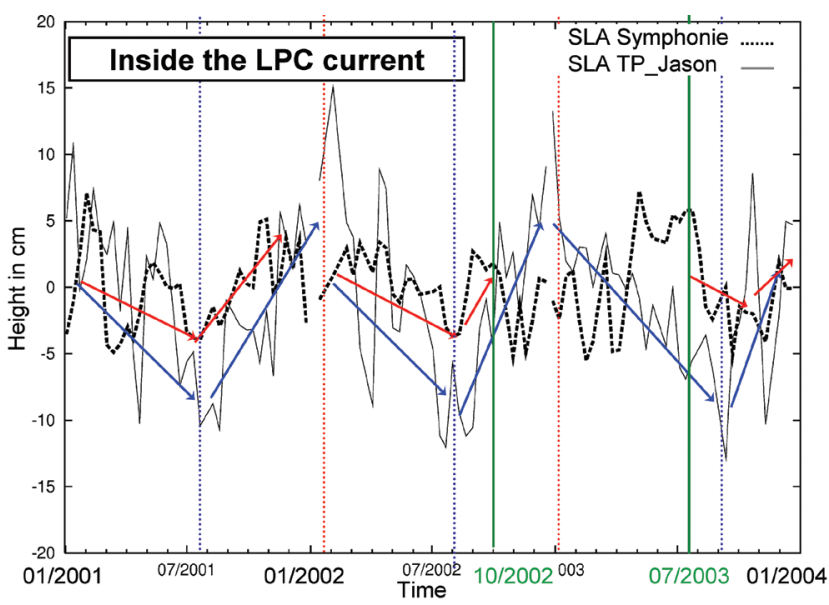

Fig. 19. SLA minus steric effect at 43.15 deg. in Latitude, 7,18 deg. in Longitude. 


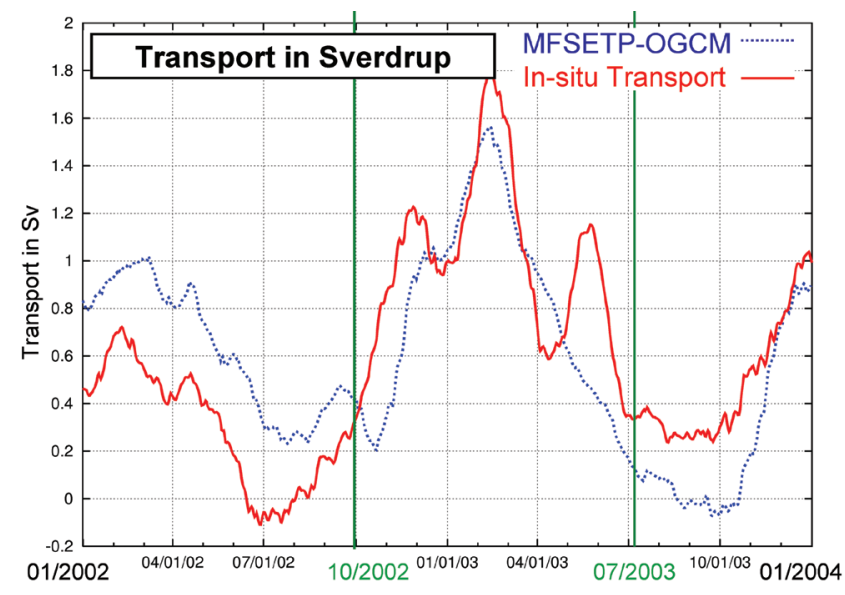

Fig. 20. Transport in the Corsica Channel: In-situ vs MFSTEP model.

$0.3 \mathrm{~Sv}$ than the in-situ one, the two signals are coherent. From October 2002 to December 2003, the current entering the model domain, which flow along the western side of Corsica, become particularly weak compared to the insitu measurements. Whereas the in-situ and the MFSTEP transports are well correlated at the beginning and at the end of the simulation, we note that between October 2002 and July 2003 the two signals are strongly different with lags and dynamic events not reproduced by the MFSTEP model. Thus, the disagreements observed between the SYMPHONIE model and altimetry during this period could therefore be due to a defect in the general circulation model used to force the regional model rather than to a bad tuning of the SYMPHONIE model. Comparison between altimetry data and SYMPHONIE can actually be used in the present case to detect such defaults. Moreover, in future simulations, the coastal altimetric dataset developed here could be considered as an alternative to force the SYMPHONIE model. Such a dataset would indeed represent a highly realistic forcing and, contrary to classical altimetric data, has sufficient spatial and temporal resolutions and covers completely the modelled area.

\section{DISCUSSIONS AND CONCLUDING REMARKS}

\subsection{Ability of Altimetry to Validate a Boussinesq Model}

This work shows the ability of a new multi-mission altimetry dataset to validate a Boussinesq model implemented in coastal areas. However, the generation of a homogeneous altimetry/model dataset is a necessary condition for such a validation. In the coastal regions, a different processing strategy is needed, including new and improved algorithms and corrections in order to increase availability of data in quantity and quality. There are still areas of improvement, especially for the re-tracking of raw waveforms in coastal zones and the computation of an improved Sea Surface Bias correction. For example, Ollivier et al. (2005) provided a method of noise reduction to improve the mean square fitting of radar altimeter echoes for the estimation of sea parameters. In addition to the re-tracking, the next step to improve the generated coastal altimetry dataset will consist of implementing a multi-satellite crossover minimization algorithm in order to eliminate residual large-scale errors (Le Traon and Ogor 1998).

\subsection{Summary of the Results}

The comparisons between the SYMPHONIE model and the coastal altimetry data show good results especially from January 2001 to September 2002 and from July to December 2003. In addition to the large-scale variability, which is well reproduced by SYMPHONIE, the smaller spatial dynamic structures along the satellite tracks are often in agreement with altimetry. However, the mesoscale and sub-mesoscale variability along the continental slopes appears difficult to predict. The SLA signal captured by altimetry is strongly dominated by the steric signal at the seasonal scale. The seasonal signal combining SYMPHONIE SLA with a spatially uniform but time dependent value exhibits a very good agreement with altimetry over the whole study domain, except for some coastal areas. Indeed these dynamic zones, located along the continental slopes, are strongly dominated by the LPC variability. In removing the steric signal in both altimetry and model inside the LPC, the intrinsic seasonal variability of the LPC is highlighted. This variability seems to be in nearly opposite phase with the steric signal, in both altimetry and SYMPHONIE (with smaller amplitude in the latter), except from September 2002 to July 2003 in the model. In future studies, the reason for such dephasing has to be investigated by means of complementary observations.

\subsection{Use of Altimetry to Optimize SYMPHONIE Simu- lations}

Knowledge of the LPC surface variability is a key point to better understand the coastal dynamical processes in the North-western Mediterranean Sea. A coastal altimetry product that allows precise monitoring of sea surface variability appears to be useful for optimization and better tuning of the boundary conditions and dynamic parameters in the SYMPHONIE model. The work presented in this paper constitutes a first step towards this purpose and has to be integrated into a more general framework, aimed at assimilating improved coastal altimetry in Boussinesq regional models over the North-western Mediterranean.

Acknowledgements The authors wish to warmly thank the CTOH/LEGOS for the provision of the raw altimeter data records (Request for altimetry products can be addressed 
to: ctoh products@notos.cst.cnes.fr). Many thanks to R. Morrow, F. Birol, and L. Roblou for encouragements and fruitful discussions about coastal altimetry. Thanks are also due to G. P. Gasparini and G. M. R. Manzella who actively collaborate to the Italian/French project "ALBICOCCA". This study was funded by the European MFSTEP Project (EU Contract EVK3-CT-2002-00075), the European INSEA Project (SST4-CT-2005-012336), the "LEFE-IDAO2006" and "OPA Symphonique" french projects. The authors thank Cyril Nguyen and the Laboratoire d'Aérologie computer team, Serge Prieur, Laurent Cabanas, Jérémy Leclercq, Didier Gazen, and Juan Escobar for their support. Valuable editing comments by Inge Jonckheere are also deeply appreciated.

\section{REFERENCES}

Ahumada, M. A., and A. Cruzado, 2006: Modelling the circulation in the Northwestern Mediterranean Sea with the Princeton Ocean Model. Ocean Sci. Discuss., 3, 1255-1292.

Alberola, C., C. Millot, and J. Font, 1995: On the seasonal and mesoscale variabilities of the Nothern Current during the PRIMO-0 experiment in the western Mediterranean Sea. Oceanol. Acta, 18, 163-192.

Arakawa, A., 1972: Design of UCLA general circulation model. Tech Report No 7, University of California, $116 \mathrm{pp}$.

Arakawa, A., and M. J. Suarez, 1983: Vertical differencing of the primitive equations in sigma coordinates. Mon. Weather Rev., 111, 34-45.

AVISO, 1996: AVISO user handbook, Merged TOPEX/ Poseïdon products, Tech. Rep. AVI-NT-02-101-CN, Ed. 3.0, 198 pp.

AVISO, 2004: AVISO and PODAAC User Handbook, IGDR and GDR Jason Products, Tech. Rep. SMMMU-M5-OP-13184-CN, Ed. 2.0, 112 pp.

Béthoux, J. P., 1980: Mean water fluxes across sections in the Mediterranean Sea, evaluated on the basis of water and salt budgets and of observed salinities. Oceanol Acta, 3, 79-88.

Blayo, E., and L. Debreu, 2005: Revisiting open boundary conditions from the point of view of characteristic variables. Ocean Model., 9, 231-252.

Blumberg, A. F., and G. Mellor, 1987: A description of a three dimensional coastal circulation model. In: Heaps, N. S. (Eds.), In Three-Dimensional Coastal Ocean Models, AGU, 1-16.

Bouffard, J., L. Roblou, Y. Ménard, P. Marsaleix, and P. De Mey, 2006 : Observing the short scale ocean variability in the Western Mediterranean Sea by using a coastal multi-satellite altimetry product and models, Proceeding of ESA Symposium, 15 years of progress in Radar Altimetry, Venice, Italy, http://earth.esa.int/workshops/ venice06/participants/971/paper 971 bouffard. pdf.

Carrere, L., and F. Lyard, 2003: Modeling the barotropic response of the global ocean to atmospheric wind and pressure forcing - comparisons with observations. Geophys. Res. Lett., 30, 1275, doi: 10:1029/2002GL016473.

Cheney, R. E., J. G. Marsh, and B. D. Beckley, 1983: Global mesoscale variability from colinear tracks of SEASAT altimeter data. J. Geophys. Res., 88, 4343-4354.

Conan, P., and C. Millot, 1995: Variability of the Northern Current of Marseilles, Western Mediterranean Sea, from February to June 1992. Oceanol. Acta, 18, 193 205.

Costanza, R., R. d'Arge, R. de Groot, S. Farber, M. Grasso, B. Hannon, K. Limburg, S. Naeem, R. O’Neill, J. Paruelo, R. Raskins, P. Sutton, and M. Belt, 1997: The value of the world's ecosystem services and natural capital. Nature, 387, 253-260.

Demirov, E., and N. Pinardi, 2002: The Simulation of the Mediterranean Sea circulation from 1979 to 1993. Part I: The interannual variability. J. Mar. Syst., 33-34, 2350.

Deng, X., W. E. Featherstone, C. Hwang, and P. Berry, 2002: Estimation of contamination of ERS-2 and Poseidon satellite radar altimetry close to the coasts of Australia. Mar. Geodesy, 25, 249-271.

Dufau-Julliand, C., P. Marsaleix, A. Petrenko, and I. Dekeyser, 2004: Three-dimensional modeling of the Gulf of Lion's hydrodynamics (northwest Mediterranean) during January 1999 (MOOGLI3 Experiment) and latewinter 1999: Western Mediterranean Intermediate Water's (WIW's) formation and its cascading over the shelf break. J. Geophys. Res., 109, C11002, doi: 10. 1029/2003JC002019.

ENVISAT RA-2/MWR Product Handbook, 2002: Tech. Rep. PO-TN-ESR-RA-0050, 342 pp.

Estournel, C., V. Kondrachoff, P. Marsaleix, and R. Vehil, 1997: The plume of the Rhone: Numerical simulation and remote sensing. Cont. Shelf Res., 17, 899-924.

Estournel, C., P. Broche, P. Marsaleix, J. L. Devenon, F. Auclair, and R. Vehil, 2001: The Rhone river plume in unsteady conditions : Numerical and experimental results. Estuar. Coast. Shelf Sci., 53, 25-38.

Estournel, C., X. Durrieu de Madron, P. Marsaleix, F. Auclair, C. Julliand, and R. Vehil, 2003 : Observation and modelisation of the winter coastal oceanic circulation in the Gulf of Lions under wind conditions influenced by the continental orography (FETCH experiment). J. Geophy. Res., 108, 7-1-7-18, doi: 10. 1029/2001JC000825.

Flather, R. A., 1976: A tidal model of the northwest European continental shelf. Memorie Societa Reale Scienze Liege, 6, 141-164.

Font, J., E. Garcia-Ladona, and E. G. Gorriz, 1995: The seasonality of mesoscale motion in the Nothern Current of 
the Western Mediterranean: Several years of evidence. Oceanol. Acta, 18, 207- 219.

Gaspar, P., Y. Gregoris, and J. Lefevre, 1990: A simple eddy kinetic energy model for simulations of the oceanic vertical mixing: Tests at station Papa and long-term upper ocean study site. J. Geophys. Res., 95, 16179 $-16193$.

Gatti, J., A. Petrenko, J. L. Devenon, Y. Leredde, and C. Ulses, 2006: The Rhone river dilution zone present in the northeastern shelf of the Gulf of Lion in December 2003. Cont. Shelf Res., 26, 1794-1805, doi: 10.1016/j. csr.2006.05.012.

Geernaert, G. L., 1990: Bulk parameterizations for the wind stress and heat fluxes, in Surface Waves and Fluxes, Current Theory, Kluwer Acad., Norwell, Mass, Vol. $1,336 \mathrm{pp}$.

GEOSAT Follow-On GDR User's Handbook, 2002: Tech. Rep. NOAA.

Gill, A., 1982: Atmosphere-Ocean dynamics. Academic Press, San Diego, 662 pp.

Gostan, J., 1967 : Résultats des observations hydrologiques effectuées entre les côtes de Provence et de Corse. Ph.D. Thesis, Univ. Paris, France.

Greatbatch, R. J., 1994: A note on the representation of steric sea level in models that conserve volume rather than mass. J. Geophys. Res., 99, 12767-12771.

Guizien, K., T. Brochier, J. C. Duchêne, B. S. Koh, and P. Marsaleix, 2006: Dispersal of owenia fusiformis larvae by wind-driven currents: turbulence, swimming behaviour and mortality in a three-dimensional stochastic model. Marine Ecology Progress Series, 311, 47-66.

Herrmann, M., S. Somot, F. Sevault, C. Estournel, and M. Déqué, 2008: Modeling the deep convection in the Northwestern Mediterranean Sea using an eddy-permitting and an eddy-resolving model: Case study of winter 1986-87. J. Geophys. Res., 113, doi: 10.1029/ 2006JC003991.

Huyer, A., 1990: Shelf circulation. In: LeMehaute, B., and D. M. Hanes (Eds.), Ocean Eng. Sci. (The Sea), 9, 423466, Wiley, New York.

Jorda, G., E. Comerma, R. Bolaños, and M. Espino, 2006: Impact of forcing errors in the CAMCAT oil spill forecasting system. A sensitivity study. J. Mar. Syst., doi: /10.1016/j.jmarsys.2005.11.016.

Jordi, A., G. Basterretxea, A. Orfila, and J. Tinboré, 2006: Operational analysis of the circulation and shelf-slope exchanges in the continental margin of the northwestern Mediterranean. Ocean Sci. Discuss., 3, 585608.

La Violette, P., 1990: The Western Mediterranean Circulation Experiment (WMCE). J. Geophy. Res., 95, 1511-1514.

Labroue, S., P. Gaspar, J. Dorendeu, O. Z. Zanifé, F. Mertz, P. Vincent, and P. Choquet, 2004: Non parametric of the sea states bias for Jason 1 radar altimeter. Mar. Geodesy, 27, 453-481.

Lacombe, H., and P. Tchernia: 1972: Caractères hydrologiques et circulation des eaux en Méditerranée. In: Stanley, D. J. (Ed.), The Mediterranean Sea, a Natural Sedimentation Laboratory, Dowden, Hutchinson and Ross, Inc. Straudsburg, PA, 25-36.

Le Traon, P. Y., and F. Ogor, 1998: ERS-1/2 orbit improvement using Topex/Poseidon: The $2 \mathrm{~cm}$ challenge. $J$ Geophys. Res., 103, 8045-8057.

Lombard, A., A. Cazenave, P. Y. Le Traon, and M. Ishii, 2005: Contribution of thermal expansion to presentday sea-level change revisited. Global Planet. Change, 47, 1-16.

Marsaleix, P., F. Auclair, and C. Estournel, 2006 : Considerations on open boundary conditions for regional and coastal ocean models. J. Atmos. Ocean. Technol., 23, 111604-111613.

Millero, F. J., and A. Poisson, 1981: International oneatmosphere equation of state for seawater. Deep-Sea Res., 28, 625-29.

Millot, C., 1987: Mesoscale and seasonal variabilities of circulation in western Mediterranean. Dyn. Atmos. Ocean., 15, 179-214.

Millot, C., 1991: Circulation in the western Mediterranean. Oceanol. Acta, 10, 143-149.

Ollivier, A., N. Le Bihan, J. L. Lacoume, and O. Z. Zanife, 2005 : Improving speckle filtering with Singular Value Decomposition to extract ocean parameters from altimetry radar echos, Proceeding of Physics in Signal and Image Processing (PSIP'2005), Toulouse.

Pattullo, J., W. Munk, R. Revelles, and E. Strong, 1955: The seasonal oscillation in sea level. J. Mar. Res., 14, 88-156.

Pedlosky, J., 1979: Geophysical Fluid Dynamics, SpringerVerlag, New York.

Petrenko, A., Y. Leredde, and P. Marsaleix, 2005: Circulation in a stratified and wind forced Gulf of Lions, NW Mediterranean Sea : In-situ and modeling data. Cont. Shelf Res., 25, 7-27, doi: 10.1016/j.csr.2004.09.004.

Pinardi, N., I. Allen, E. Demirov, P. De Mey, G. Korres, A. Lascaratos, P. Y. Le Traon, C. Maillard, G. Manzella, and C. Tziavos, 2003: The Mediterranean ocean forecasting system: First phase of implementation (1998 - 2001). Ann. Geophys., 21, 3-20.

Reid, J., and A. W. Mantyla, 1976: The effect of the geostrophic flow upon sea alevation in the Nothern north Pacific Ocean. J. Geophys. Res., 81, 3100-3110.

Ries, J. C., and B. D. Tapley, 1999: Centimeter level orbit determination for the TOPEX/Poseidon altimeter satellite, Proceedings of the ASS/AIAA Space Flight Mechanism Meeting, Breckenridge, CO, USA, 583597.

Sammari, C., C. Millot, and L. Prieur, 1995: Aspects of sea- 
sonal and mesoscale variabilities of the Nothern Current in the western Mediterranean Sea inferred from PROLIG-2 and PROS-6 experiments. Deep-Sea Res., 42, 893-917.

Send, U., J. Font, G. Krahmann, C. Millot, M. Rhein, and J. Tintoré, 1999: Recent advances in observing the physical oceanography of the western Mediterranean Sea. Prog. Oceanogr., 44, 37-64.

SSALTO/DUACS User Handbook: (M)SLA and (M)ADT Near-Real Time and Delayed Time Products. SALPMU-P-EA-21065-CLS.

Tai, C. K., 1989: Accuracy assessment of widely used orbit error approximations in satellite altimetry. J. Atmos. Ocean. Technol., 6, 147-150.

Tai, C. K., 1991: How to observe the gyre to global-scale variability in satellite altimetry:signal attenuation by orbit error removal. J. Atmos. Ocean. Technol., 8, 272288.

Taillandier, V., and A. Griffa, 2006: Implementation for ARGO floats in a realistic Mediterranean Sea OPA model twin experiment testing. Ocean Sci. Discuss., 3, 255-289.
Ulses, C., C. Grenz, P. Marsaleix, E. Schaaff, C. Estournel, S. Meulé, and C. Pinazo, 2005: Circulation in a semi enclosed bay under the influence of strong fresh water input. J. Mar. Syst., 56, 113-132, doi: 10.1016/j. jmarsys.2005.02.001.

Van Gysen, H., R. Colemen, R. Morrow, B. Hirsch, and C. Risos, 1992: Analysis of collinear passes of satellites altimeter data. J. Phys. Oceanogr., 20, 1742-1760.

Vignudelli, S., P. Cipollini, M. Astraldi, G. P. Gasparini, and G. M. R. Manzella, 2000: Integrated use of altimeter and in situ data for understanding the water exchanges between the Tyrrhenian and Ligurian Seas. $J$. Geophys. Res., 105, 19649-19663.

Vignudelli, S., P. Cipollini, L. Roblou, F. Lyard, G. P. Gasparini, G. R. M. Manzella, and M. Astraldi, 2005: Improved satellite altimetry in coastal systems: Case study of the Corsica Channel (Mediterranean Sea). Geophys. Res. Lett., 32, L07608, doi: 1029/2005GL22602.

Zlotnicki, V., L. L. Fu, and W. Patzert, 1989. Seasonal variability in global sea level observed with Geosat altimetry. J. Geophys. Res., 94, 17959-17969. 